\title{
Synthesis of Some Azo Disperse Dyes Based on Pyridone Moiety and Their Application on Polyester Fabrics
}

\author{
Morsy A. EL-Apasery ${ }^{* 1}$, Salah Shakra ${ }^{1}$, Dina Abbas ${ }^{1}$, Hatem E. Gaffer ${ }^{1}$ and \\ Emad A. Allam ${ }^{2}$ \\ ${ }^{1}$ Dyeing, Printing and Textile Auxiliaries Department, Textile Research Division, \\ National Research Centre, 33 El Buhouth St., Dokki, Cairo, Egypt. \\ ${ }^{2}$ Textile Printing, Dyeing and Finishing Department, Faculty of Applied Arts, Helwan \\ University, Cairo, Egypt.
}

\footnotetext{
7 HEAIM of this work was to prepare a series of some azo disperse dyes based on pyridones moiety. The prepared dyes were used for dyeing polyester fabric. The chemical structure and dyeing performance of these dyes were investigated.
}

\section{Introduction}

The wide spreading of Disperse dyes has a good impact in the field of textile industry while the discovery of synthetic fabrics especially polyester fabric. Disperse dyes are a kind of dyes which have impossibility to solve in water and these make their affinity for hydrophobic fabric such as cellulose acetate, nylon, polyester [1]. The particles of disperse dyes appear in suspension states in the water bath in the presence of dispersing agent [2]. Pyridones derivatives become a major area of research and an important branch in preparing dyes. Disperse dyes which are based on pyridone moiety as a coupling component have a great impact in dyestuff industry [3] because of their excellent fastness properties like perspiration, good light fastness and wash fastness, also their physicochemical properties make them play an important role in manufacturing photoactive materials. Pyridone derivatives are used as antibacterial agent which has a great effect in pharmaceutical sciences [4]. Different anilines disperse dyes were prepared and used in dyeing polyester fibers with different shades starting from, yellow to greenish yellow [5]. In conjunction to our previous effort for synthesis new disperse dyes [6], we report herein the synthesis of some new disperse dyes based on pyridone moiety and study their dyeing performance for dyeing polyester fabrics with different dyeing methods.

\section{Materials and Methods}

\section{Materials}

Scoured and bleached 100\% polyester fabric $\left(149 \mathrm{~g} / \mathrm{m}^{2}\right)$ was supplied by El-Mahalla El-Kobra Company. The fabric was treated before dyeing with a solution containing nonionic detergent (Hostapal CV, Clariant-Egypt, $5 \mathrm{~g} / \mathrm{L}$ ) and sodium carbonate $(2 \mathrm{~g} / \mathrm{L})$ in a ratio of $50: 1$ at $60{ }^{\circ} \mathrm{C}$ for 30 $\mathrm{min}$, thoroughly washed with water, and air dried at room temperature.

General procedure for the synthesis of azo disperse dyes $8 a-f$

A cold solution of aryldiazonium salt (10 $\mathrm{mmol})$, (prepared by adding a solution of sodium nitrite $\left(1.00 \mathrm{~g}\right.$ in $\left.10 \mathrm{~mL} \mathrm{H}_{2} \mathrm{O}\right)$ to a cold solution of arylamine hydrochloride (10 mmol) with stirring as described earlier) (3). The resulting solution of the aryldiazonium chloride was then added to a cold solution of compound $\mathbf{6 a}, \mathbf{b}(10 \mathrm{mmol})$ in ethanol $(20 \mathrm{~mL})$ containing sodium acetate $(2.00 \mathrm{~g})$. The mixture was stirred at room temperature for one $\mathrm{hr}$ and the solid product so formed was collected by filtration and re-crystallized from proper solvent. Dyes $8 \mathrm{a}-\mathrm{d}$ were recently prepared $[6,7]$.

1,4-Diethyl-5-[(2-hydroxy-phenyl)hydrazono]-2,6-dioxo-1,2,5,6-tetrahydropyridine-3-carbonitrile ( 8 e)

Yield $2.14 \mathrm{~g}(68 \%)$, m.p. $148-150{ }^{\circ} \mathrm{C}$. IR $(\mathrm{KBr}): \mathrm{v}=3370 \mathrm{~cm}^{-1}(\mathrm{OH}), 3298 \mathrm{~cm}^{-1}(\mathrm{NH}), 2100$ $\mathrm{cm}^{-1}(\mathrm{CN}), 1704,1635 \mathrm{~cm}^{-1}(2 \mathrm{CO}) . \mathrm{MS}: \mathrm{m} / \mathrm{z}=$ $311\left(\mathrm{M}^{-1}, 100 \%\right), 297(11 \%), 267(7 \%), 241(5 \%)$, 107(14\%), 79(11\%).

*Corresponding author e-mail: elapaserym@yahoo.com 
1,4-diethyl-5-(2-(3-nitrophenyl)hydrazono)2,6-dioxo-1,2, 5, 6-tetrahydropyridine-3carbonitrile (8f).

Yield 2.12 g (63\%), m.p. $292-294^{\circ} \mathrm{C}$. IR (KBr): $v=3265 \mathrm{~cm}^{-1}(\mathrm{NH}), 2219 \mathrm{~cm}^{-1}(\mathrm{CN}), 1673,1630$ $\mathrm{cm}^{-1}$ (2CO). $340\left(\mathrm{M}^{-1} 100 \%\right), 326(17 \%), 393(18 \%)$, 267(12\%), 250(16\%), 138(18\%), 91(12\%).

\section{Dyeing}

Conventional dyeing method (Carrier method)

Samples ( $2 \mathrm{~g}$ ) were introduced into a flask containing a dyebath of $2 \%$ (w.o.f) dye shade and (Avolan IS) as dispersing agent 1-4\%, commercial $\mathrm{HC}$ carrier (Liquid) supplied by Egyptian Turkish Co. (Cairo, Egypt) for auxiliaries with ratio $2 \%$ (w.o.f) at $100{ }^{\circ} \mathrm{C}$ with a 1:50 liquor ratio. During dyebath preparation, the dye was mixed with 10 drops of DMF and then mixed with dispersing agent, and water was added to prepare a homogeneous dispersion of the dye. The $\mathrm{pH}$ was adjusted to 4.5 by using acetic acid. At the end of the dyeing process after $1 \mathrm{~h}$, the dyed samples were removed, rinsed in warm water, and subjected to reduction clearing in a solution comprising $2 \mathrm{~g} / \mathrm{L}$ of sodium hydrosulphite and $2 \mathrm{~g} / \mathrm{L}$ of sodium hydroxide (caustic soda) for 10 min at $60^{\circ} \mathrm{C}$, with a liquor ratio of $1: 40$, and the reduction-cleared sample was rinsed thoroughly in water. The dyed samples were removed, rinsed in tap water, and allowed to dry in the open air [6].

High temperature dyeing method (HT)

A dispersion of the dye was produced by dissolving the appropriate amount of dye $(2 \%$ shade) in 10 drops of DMF and then added dropwise with stirring to the dye bath (Liquor ration 50:1) containing sodium lignin sulfonate as dispersing agent $1-4 \%$. The ratio of dispersing agent to dyestuff is 4 to 1 . The $\mathrm{pH}$ of the dye bath was adjusted to 4.5 using acetic acid and the wetted polyester fabrics were added. Dyeing was performed by raising the dye bath temperature to $130{ }^{\circ} \mathrm{C}$ under pressure in a dyeing machine at a rate of $15^{\circ} \mathrm{C} / \mathrm{min}$, holding at this temperature for $60 \mathrm{~min}$ and then cooling to $50{ }^{\circ} \mathrm{C}$. After dyeing, the fabrics were thoroughly washed and subjected to surface reduction clearing $((2 \mathrm{~g} \mathrm{NaOH}+2$ $\mathrm{g}$ sodium hydrosulphite)/L The samples were washed and air-dried.

\section{Colour measurements and analyses \\ Colour measurements}

The color yields of the dyed samples were determined by using the light reflectance technique performed on a Perkin-Elmer (Lambda 3B) UV/ VIS Spectrophotometer. The color strengths, expressed as $\mathrm{K} / \mathrm{S}$ values, were determined by applying the Kubelka-Mink equation [8,9].

Color Fastness tests

Fastness properties of the dyed samples were tested to washing, rubbing, perspiration, and light fastness according to AATCC standard tests [10$12]$.

\section{Results and Discussion}

Pyridones $\mathbf{6 a}, \mathbf{b}$ are prepared by reacting ethyl cyanoacetate, with ethyl amine to produce amide derivatives 4 , which reacts with ethylacetoacetate or methyl propionylacetate to afford the target compounds ( $c f$. Scheme 1). Coupling of compounds $\mathbf{6 a , b}$ with aromatic diazonium salts afforded the arylhydrazono disperse dyes 8a-f based on pyridone moiety ( $c f$. Scheme 1).

Disperse dyes 8a-f were applied to polyester fabrics using both high temperature dyeing method (HT) at $130{ }^{\circ} \mathrm{C}$ and/or carrier dyeing method. Yellow, dark yellow, and brown color shades were obtained. The dyeing properties on the polyester fabrics were evaluated in terms of their fastness properties (e.g., fastnesses to washing, rubbing, light, and perspiration). Tables 1 and 2 show the colour of dyeing on polyester fabrics is expressed in terms of CIELAB coordinates as: lightness $\left(\mathrm{L}^{*}\right) ; a^{*}$ (red - green); and $b^{*}$, (yellow - blue). The data listed in Tables 3 and 4 show that the high temperature dyeing method displayed very good fastness levels to washing, rubbing and perspiration, while, the carrier dyeing method has good fastness levels to washing, rubbing and perspiration. The light fastness properties are fair in both different dyeing methods.

Effect of dispersing agent concentration on the $K / S$ using carrier

Table 5 shows the relationship between K/S as a parameter for dye uptake and the concentrations of the dispersing agent used from 1 to $4 \%$, generally, the values K/S decrease with increasing amount of dispersing agent applied at both 100 and $130^{\circ} \mathrm{C}$. 


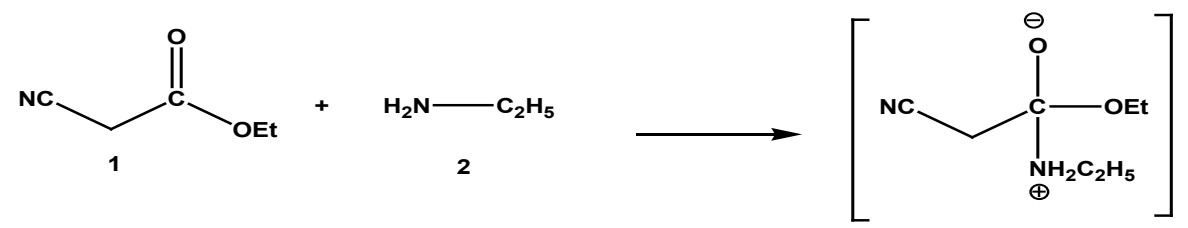<smiles>[2H]C1=C(C#N)C(=O)N(CC)C(=O)C1</smiles>
$\begin{aligned} \text { 6a, } \mathrm{R} & =\mathrm{CH}_{3} \\ \mathrm{~b}, \mathrm{R} & =\mathrm{C}_{2} \mathrm{H}_{5}\end{aligned}$<smiles>[2H]C1=C(C#N)C(=O)N(CC)C(=O)C1</smiles>

6

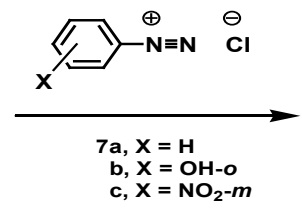

b, $X=\mathrm{OH}-\mathrm{O}$
c, $X=\mathrm{NO}_{2}-m$<smiles>[R]C1=C(C#N)C(=O)N(CC)C(=O)/C1=N/Nc1ccccc1[Y]</smiles>

8a, $\mathrm{R}=\mathrm{CH}_{3}, \quad \mathrm{X}=\mathbf{H}$

b, $\mathrm{R}=\mathrm{CH}_{3}, \quad \mathrm{X}=\mathrm{OH}-\mathrm{O}$

c, $\mathrm{R}=\mathrm{CH}_{3}, \quad X=\mathrm{NO}_{2}-m$

$\mathrm{d}, \mathrm{R}=\mathrm{C}_{2} \mathrm{H}_{5}, \quad \mathrm{X}=\mathrm{H}$

$\begin{array}{ll}e, R=\mathrm{C}_{2} \mathrm{H}_{5}, & X=\mathrm{OH}-\mathrm{o} \\ \text { f, } \mathrm{R}=\mathrm{C}_{2} \mathrm{H}_{5}, & X=\mathrm{NO}_{2}-m\end{array}$

TABLE 1. Optical measurements of the synthesized disperse dyes 8a-f on polyester fabric at $100{ }^{\circ} \mathrm{C}$.

\begin{tabular}{cccccc}
\hline Dye NO. & Absorption $\lambda_{\max } / \mathbf{n m}$ & $\mathbf{L}^{*}$ & $\boldsymbol{a}^{*}$ & $\boldsymbol{b}^{*}$ & $\mathbf{K} / \mathbf{S}$ \\
\hline $8 \mathrm{a}$ & 440 & 75.88 & -6.66 & 90.47 & 25.98 \\
$8 \mathrm{~b}$ & 470 & 67.57 & 16.72 & 55.98 & 6.36 \\
$8 \mathrm{c}$ & 435 & 76.13 & -8.77 & 71.94 & 10.48 \\
$8 \mathrm{~d}$ & 440 & 74.26 & -3.23 & 88.48 & 25.84 \\
$8 \mathrm{e}$ & 440 & 63.79 & 14.23 & 51.21 & 6.88 \\
$8 \mathrm{f}$ & 430 & 64.09 & 14.46 & 72.53 & 26.91 \\
\hline
\end{tabular}


TABLE 2. Optical measurements of the synthesized dyes disperse dyes 8a-f on polyester fabric at $130{ }^{\circ} \mathrm{C}$.

\begin{tabular}{cccccc}
\hline Dye NO. & Absorption $\lambda_{\max } / \mathbf{n m}$ & $\mathbf{L}^{*}$ & $\boldsymbol{a}^{*}$ & $\mathbf{b}^{*}$ & $\mathbf{K} / \mathbf{S}$ \\
\hline $8 \mathrm{a}$ & 440 & 72.24 & 1.80 & 90.82 & 27.39 \\
$8 \mathrm{~b}$ & 470 & 54.19 & 25.20 & 56.95 & 17.33 \\
$8 \mathrm{c}$ & 435 & 73.96 & -1.42 & 83.03 & 20.77 \\
$8 \mathrm{~d}$ & 445 & 74.42 & 1.80 & 93.82 & 28.22 \\
$8 \mathrm{e}$ & 440 & 49.64 & 18.09 & 44.75 & 15.22 \\
$8 \mathrm{f}$ & 430 & 64.92 & 12.75 & 72.84 & 28.36 \\
\hline
\end{tabular}

In both dyeing methods disperse dyes $8 \mathrm{c}$ and $8 \mathrm{f}$ (having electron-attracting nitro group) show better light fastness (6) than disperse dyes $8 \mathrm{~b}$ and $8 \mathrm{e}$ (having electron donating hydroxyl group).

TABLE 3. Fastness properties of the synthesized disperse dyes $8 \mathrm{a}-\mathrm{f}$ on polyester fabrics at $100^{\circ} \mathrm{C}$.

\begin{tabular}{|c|c|c|c|c|c|c|c|c|c|c|c|c|}
\hline \multirow{3}{*}{$\begin{array}{l}\text { Dye } \\
\text { No. }\end{array}$} & \multicolumn{3}{|c|}{ Washing } & \multicolumn{6}{|c|}{ Perspiration } & \multicolumn{2}{|c|}{ Rubbing } & \multirow{3}{*}{$\begin{array}{l}\text { Light } \\
(40 \mathrm{~h})\end{array}$} \\
\hline & \multirow{2}{*}{ ALT } & \multirow{2}{*}{ SC } & \multirow{2}{*}{ SW } & \multicolumn{3}{|c|}{ Acid } & \multicolumn{3}{|c|}{ Alkali } & \multirow{2}{*}{ Wet } & \multirow{2}{*}{ Dry } & \\
\hline & & & & ALT & SC & SW & ALT & SC & SW & & & \\
\hline $8 \mathrm{a}$ & $4-5$ & $4-5$ & $4-5$ & $4-5$ & $4-5$ & 4 & $4-5$ & $4-5$ & 4 & 4 & $4-5$ & 6 \\
\hline $8 b$ & $4-5$ & $4-5$ & 4 & 4 & 4 & 4 & $4-5$ & 4 & 4 & $3-4$ & $3-4$ & $4-5$ \\
\hline $8 \mathrm{c}$ & 4 & $4-5$ & 4 & $4-5$ & $4-5$ & $4-5$ & $4-5$ & $4-5$ & 4 & $3-4$ & $3-4$ & 6 \\
\hline $8 \mathrm{~d}$ & $4-5$ & $4-5$ & $4-5$ & $4-5$ & $4-5$ & $4-5$ & $4-5$ & $4-5$ & $4-5$ & 4 & $4-5$ & 6 \\
\hline $8 \mathrm{e}$ & 4 & $4-5$ & 4 & 4 & 4 & 4 & $4-5$ & 4 & 4 & $3-4$ & $4-5$ & $4-5$ \\
\hline $8 \mathrm{f}$ & $4-5$ & $4-5$ & $4-5$ & 4 & 4 & 4 & 4 & 4 & 4 & $3-4$ & $4-5$ & 6 \\
\hline
\end{tabular}

TABLE 4. Fastness properties of the synthesized disperse dyes $8 \mathrm{a}-\mathrm{f}$ on polyester fabrics at $130^{\circ} \mathrm{C}$.

\begin{tabular}{|c|c|c|c|c|c|c|c|c|c|c|c|c|}
\hline \multirow{3}{*}{$\begin{array}{l}\text { Dye } \\
\text { No. }\end{array}$} & \multicolumn{3}{|c|}{ Washing } & \multicolumn{6}{|c|}{ Perspiration } & \multicolumn{2}{|c|}{ Rubbing } & \multirow{3}{*}{$\begin{array}{l}\text { Light } \\
\text { (40h) }\end{array}$} \\
\hline & \multirow{2}{*}{ ALT } & \multirow{2}{*}{$\mathrm{SC}$} & \multirow{2}{*}{ SW } & \multicolumn{3}{|c|}{ Acid } & \multicolumn{3}{|c|}{ Alkali } & \multirow{2}{*}{ Wet } & \multirow{2}{*}{ Dry } & \\
\hline & & & & ALT & $\mathrm{SC}$ & SW & ALT & $\mathrm{SC}$ & SW & & & \\
\hline $8 \mathrm{a}$ & $4-5$ & $4-5$ & $4-5$ & $4-5$ & $4-5$ & $4-5$ & $4-5$ & $4-5$ & 4 & $4-5$ & $4-5$ & 6 \\
\hline $8 b$ & 4 & 4 & 4 & $4-5$ & $4-5$ & 4 & $4-5$ & 4 & 4 & $4-5$ & $4-5$ & $4-5$ \\
\hline $8 \mathrm{c}$ & $4-5$ & $4-5$ & $4-5$ & $4-5$ & $4-5$ & $4-5$ & $4-5$ & $4-5$ & $4-5$ & $4-5$ & 5 & 6 \\
\hline $8 \mathrm{~d}$ & $4-5$ & $4-5$ & $4-5$ & $4-5$ & $4-5$ & 4 & $4-5$ & $4-5$ & 4 & $4-5$ & $4-5$ & 6 \\
\hline $8 \mathrm{e}$ & $4-5$ & $4-5$ & $4-5$ & $4-5$ & $4-5$ & 4 & $4-5$ & $4-5$ & 4 & $4-5$ & $4-5$ & $4-5$ \\
\hline $8 \mathrm{f}$ & $4-5$ & $4-5$ & $4-5$ & $4-5$ & $4-5$ & 4 & 4 & 4 & 4 & $4-5$ & $4-5$ & 6 \\
\hline
\end{tabular}


TABLE 5. Effect of concentration of dispersing agent on the K/S using carrier $2 \% \mathrm{~g} / \mathrm{l}$.

\begin{tabular}{|c|c|c|c|c|c|c|}
\hline \multirow[b]{2}{*}{$\begin{array}{l}\text { Dye } \\
\text { No. }\end{array}$} & \multicolumn{3}{|c|}{ Dyeing at $100{ }^{\circ} \mathrm{C}$} & \multicolumn{3}{|c|}{ Dyeing at $130{ }^{\circ} \mathrm{C}$} \\
\hline & $\begin{array}{l}\text { Concentration of } \\
\text { dispersing agent }\end{array}$ & $\begin{array}{c}\text { Absorption } \\
\lambda_{\max } / \mathbf{n m}\end{array}$ & $\mathbf{K} / \mathbf{S}$ & $\begin{array}{l}\text { Concentration of } \\
\text { dispersing agent }\end{array}$ & $\begin{array}{c}\text { Absorption } \\
\lambda_{\max } / \mathbf{n m}\end{array}$ & $\mathbf{K} / \mathbf{S}$ \\
\hline \multirow{4}{*}{$8 \mathrm{a}$} & 1 & \multirow{4}{*}{440} & 21.35 & 1 & \multirow{4}{*}{440} & 32.84 \\
\hline & 2 & & 19.82 & 2 & & 32.27 \\
\hline & 3 & & 20.39 & 3 & & 32.55 \\
\hline & 4 & & 20.70 & 4 & & 32.62 \\
\hline \multirow{4}{*}{$8 b$} & 1 & \multirow{4}{*}{470} & 5.47 & 1 & \multirow{4}{*}{470} & 18.96 \\
\hline & 2 & & 4.92 & 2 & & 15.36 \\
\hline & 3 & & 5.05 & 3 & & 15.53 \\
\hline & 4 & & 5.13 & 4 & & 18.96 \\
\hline \multirow{4}{*}{$8 \mathrm{c}$} & 1 & \multirow{4}{*}{435} & 10.19 & 1 & \multirow{4}{*}{435} & 23.31 \\
\hline & 2 & & 8.74 & 2 & & 21.95 \\
\hline & 3 & & 9.15 & 3 & & 22.67 \\
\hline & 4 & & 9.91 & 4 & & 23.13 \\
\hline \multirow{4}{*}{$8 d$} & 1 & \multirow{4}{*}{360} & 21.18 & 1 & \multirow{4}{*}{360} & 23.34 \\
\hline & 2 & & 17.81 & 2 & & 16.87 \\
\hline & 3 & & 21.06 & 3 & & 17.74 \\
\hline & 4 & & 21.13 & 4 & & 22.00 \\
\hline \multirow{4}{*}{$8 \mathrm{e}$} & 1 & \multirow{4}{*}{470} & 6.10 & 1 & \multirow{4}{*}{470} & 20.79 \\
\hline & 2 & & 5.39 & 2 & & 19.26 \\
\hline & 3 & & 5.64 & 3 & & 20.02 \\
\hline & 4 & & 5.74 & 4 & & 20.31 \\
\hline \multirow{4}{*}{$8 f$} & 1 & \multirow{4}{*}{430} & 23.15 & 1 & \multirow{4}{*}{430} & 28.41 \\
\hline & 2 & & 22.77 & 2 & & 26.66 \\
\hline & 3 & & 22.93 & 3 & & 27.86 \\
\hline & 4 & & 23.09 & 4 & & 27.95 \\
\hline
\end{tabular}

\section{Conclusion}

Coupling of 4-methy pyridone-3-carbonitrile or 4-ethyl pyridone-3-carbonitrile with aromatic diazonium salts affords a series of disperse dyes. Disperse dyes having electron withdrawing group show better light fastness than dyes having electron donating group. Also, for both dyeing methods, the dye uptake expressed as K/S decrease with increasing the amount of dispersing agent.

\section{References}

1. Osman H. and Khairy M., Optimization of polyester printing with disperse dyes nano printing, India Journal Of Fibre And Textile Research, 202 (2013).

2. Arthur D. Broadbent, Basic Principles of Textile Coloration, Society of Dyers and Colourists, 307 (2001).

3. Alya Al-Etaibi, Morsy Ahmed El-Apasery, Huda Mahmoud, and Nouria Al-Awadi, Synthesis, characterization and antimicrobial activity, and applications of new azo pyridone, European Journal of Chemistry, 321 (2014).

4. Ismail Ajaj, Fathi H. Assaleh, Jasmina Markovski, Milica Ranc, Danijela

Egypt.J.Chem. Special Issue (2017) 
Brkovic, Milos Milc and Aleksandar D. Marinkovic, Solvatochromism and azohydrazotautomerismof novel arylazopyridone dyes, Arabian Journal of Chemistry, 2 (2015).

5. Jasmina Dostanic, Natasa Valentic, Gordana Uscumlic and Dusan Mijin, Synthesis of 5-(substituted phenylazo)-6-hydroxy-4methyl-3-cyano-2-pyridones from ethyl 3-oxo-2-(substituted phenylazo)butanoates. J. Serb. Chem. Soc. 76 (4), 499-504 (2011).

6. Alya Al-Etaibi, Morsy A. El-Apasery and Nouria Al-Awadi. The effect of dispersing agent on the dyeing of polyester fabrics with disperse dyes derived from 1, 4-diethyl-2, 6-dioxo-1, 2, 5, 6-tetrahydropyridine-3carbonitrile. European Journal of Chemistry, 4 (3), 240-244 (2013)

7. Kurenkaka Johnson Sakoma, Kasali Ademola Bello and Mohammed Kabir Yakubu, synthesis of some azo disperse dyes from 1-substituted 2-hydroxy-6-pyridone derivatives and their colour assessment on polyester fabric. Open Journal of Applied Sciences, 2, 54-59 (2012).
8. Arcoria A., Cerniani A., De Giorgy R., Longo M.L. and Toscano R.M., Carrier dyeing of polyester fibre with some disperse azo dyes, Dyes Pigments, 11 (4), 269-276 (1989).

9. Al-Etaibi A.M., El-Apasery M.A., Huda H.M. and Al-Awadi, N.A., Molecules 17, 4266-4280 (2012).

10. Al-Mousawi S.M., El-Apasery M.A. and Mahmoud H. M., Molecules, 18, 7081-7092 (2013).

11. Chrysler L.P., Methods of Test for Color Fastness of Textiles and Leather, $7^{\text {th }}$ ed., Bradford, London, 89-94 (1990).

12. El-Apasery M.A., Al-Qalaf F., Almohammad K. and Mahmoud H., Eur. J. Chem, 4 (3), 211-215 (2013).

(Received 5/9/2017; accepted 12/10/2107)

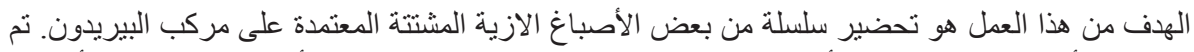

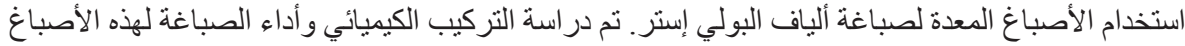

